\title{
The Photometric Estimation of Luciferase in Luminous Bacterial Cells ${ }^{1}$
}

\author{
CHARLES H. BURNS, A. D. NEVILI, AND G. HOYT WHIPPLE \\ From the School of Public Health, The University of Michigan, Ann Arbor, Michigan
}

Received August 17, 1962

Recent studies have shown that the luminescence of luminous bacteria under certain conditions responds to ionizing radiation instantaneously (1) and, under other conditions, responds to doses as low as 500 rads (2). The intensity of the luminescence is proportional to the rate of the luciferase reaction taking place in vivo. Thus radiation effects both on the metabolic system supporting the luciferase reaction (3) and on the enzyme itself may contribute to the observed response. In order to evaluate the relative contributions of these two actions, it is necessary to establish a method for the assay of active luciferase in the cells. This paper deseribes an assay based on measurement of the luminous intensity of the luciferase reaction. Applications of this method will be found for irradiated cells (3) and for growing cells (4).

The procedure is derived from the work of Strehler and Cormier (5), McElroy et al. (6), and Strehler (7), who identified the reaction components required for maximum luminescence in cell-free extracts of Photobacterium fischeri. These components are reduced riboflavin phosphate (reduced flavin mononucleotide, $\mathrm{FMNH}_{2}$ ), palmitic or other homologous aldehyde (5), oxygen, and the bacterial extract (luciferase). The cell-free extracts also contain an FMN-linked diphosphopyridine nucleotide (DPNH) oxidase which permits the substitution of a steadystate $\mathrm{FMNH}_{2}$-generating system for the spontaneously autoxidizable $\mathrm{FMNH}_{2}$. Nothing presently understood about the mechanism of the luciferase reaction suggests a method for measuring luciferase activity on a chemical basis.

The extracts referred to above were prepared by lysing the cells in deionized water and removing the cell debris by highspeed centrifugation to obtain an optically clear solution. The present assay was based on these crude extracts because no method of purification exists which permits the necessary total recovery of enzyme. When such extracts are

${ }^{1}$ This work was supported by Grant 2028A from the National Institutes of Health. for which we are deeply grateful. 
used, however, the desired direct proportionality between enzyme concentration and enzyme activity (in this case the light intensity produced by the reaction) is not obtained with either the reaction initiated by $\mathrm{FMNH}_{2}$ or that initiated by the combination of DPNH and FMN. Although it is possible to demonstrate a proportional relation in the case of the $\mathrm{FMNH}_{2}$-initiated reaction using purified luciferase preparations (8), the reaction goes to completion in a matter of seconds, making the maximum intensity of the luminescence difficult to measure. The reaction initiated by DPNH plus FMN, on the other hand, approaches steadystate conditions lasting several minutes, but the maximum light intensity produced in this case is the result of two consecutive enzymic processes rather than one.

Despite the absence of direct proportionality between light intensity and enzyme concentration, they are found to follow a straight-line relationship for each reaction when plotted on log-log coordinates. This allows one to normalize different sets of values with a single constant and to observe departures from the normal relation.

Among the other requirements of a suitable assay procedure that have been met are the following: $(a)$ assurance that the procedure extracts all of the luciferase available in the cells, $(b)$ assurance that the deterioration of the enzyme and of the reaction components at $0^{\circ} \mathrm{C}$ (storage) and at 12 and $25^{\circ}$ (reaction) is not a factor in the assay, (c) establishment of the optimum concentration of reaction components for luminescence, since FMN has been reported to be inhibiting at high concentrations (9), and $(d)$ determination of a temperature for the $\mathrm{FMNH}_{2}$-initiated reaction which permits thorough mixing of enzyme and substrates before maximum luminous intensity is reached.

\section{METHODS}

\section{Materials and Equipment}

The cell suspensions used in these studies were either growing cell suspensions which had reached maximum luminous intensity, or nonproliferating cell suspensions prepared from growing cell suspensions at maximum luminous intensity. The methods used to prepare these suspensions are similar to those used by Farghaly (10) and by Whipple (2).

The reaction components for the DPNH-FMN, or "slow" reaction, were prepared in individual stock solutions. Decanal (capric aldehyde) was chosen as the aldehyde because it is easily solubilized in water. Two working solutions were prepared from the four stock solutions: solution $\mathrm{AB}$ contained aldehyde and phosphate buffer; solution DF contained DPNH and FMN. Table 1 gives the pertinent information for the stock 
TABLE 1

Reaction Components and Their Concentrations dis l'sed in Standard Assay Procedures

\begin{tabular}{|c|c|c|c|c|c|c|}
\hline $\begin{array}{l}\text { Stock } \\
\text { soln. }\end{array}$ & Component & M.W. & $\begin{array}{l}\text { Concen. in } \\
\text { stock soln. } \\
(M)\end{array}$ & $\begin{array}{l}\text { MIl stock } \\
\text { soln. } \\
\text { in } 15 \mathrm{ml} \\
\text { working } \\
\text { soln.a }\end{array}$ & $\begin{array}{c}\text { Concu. in } \\
\text { working solı. } \\
\text { (iII) }\end{array}$ & $\begin{array}{l}\text { Concn. } \\
\text { in final } \\
\text { reaction } \\
\text { mix. } \\
(\mu \text { mole } / \mathrm{ml})\end{array}$ \\
\hline \multicolumn{7}{|c|}{ For both reactions: } \\
\hline A & $\begin{array}{l}\text { Decanal } \\
\text { Tween-20 }\end{array}$ & 156 & $\begin{array}{c}5.3 \times 10^{-2} \\
1.5 \%\end{array}$ & 2.11 & $\begin{array}{c}7.0 \times 10^{-3} \\
0.2 \%\end{array}$ & $\begin{array}{l}1.2 \\
0.033^{i} / \mathrm{C}\end{array}$ \\
\hline B & Buffer: ${ }^{d}$ & & & 7.5 & & \\
\hline & $\mathrm{KH}_{2} \mathrm{PO}_{4}$ & 136 & 0.27 & & $1.35 \times 10^{-1}$ & 22.5 \\
\hline & $\mathrm{Na}_{2} \mathrm{HPO}_{4}$ & 142 & 0.27 & & $1.35 \times 10^{-1}$ & 22.5 \\
\hline & $\mathrm{NaCl}$ & 58.5 & 0.02 & & $10^{-2}$ & 1.7 \\
\hline \multicolumn{7}{|c|}{ For slow reaction: } \\
\hline I) & I)PNH ${ }^{\varepsilon}$ & 709 & $8 \times 10^{-3 f}$ & 3.0 & $1.6 \times 10^{-3}$ & 0.27 \\
\hline $\mathbf{F}$ & $\mathrm{FMN}^{\theta}$ & 514 & $1.5 \times 1^{-4 h}$ & 1.0 & $1.0 \times 10^{-n}$ & 0.0017 \\
\hline \multicolumn{7}{|c|}{ For fast reaction: } \\
\hline$F$ & FMN & 514 & $1.5 \times 10^{-4}$ & $12.0^{i}$ & $1.2 \times 10^{-4}$ & 0.02 \\
\hline
\end{tabular}

${ }^{a}$ Solutions A, B, and Tween-20 combined in working solution AB; solutions $\mathrm{D}$ and $\mathrm{F}$ combined in working solution DF. The remainder is distilled and deionized water $\left(\mathrm{H}_{3} \mathrm{O}\right)$.

"Capric aldehyde, sp.gr. 0.828, Polak's Frutal Works, Middletown, N.Y.

$c 0.2 \mathrm{ml}$ purified liquid to $20 \mathrm{ml}$ with aqueous $1.5 \%$ Tween-20.

${ }^{d}$ Buffer adopted from the work of McElroy and Green (8), final $\mathrm{pH} 6.8$.

- Disodium salt, assay $80 \%$ or above, California Corporation for Biochemical Research.

$f 70 \mathrm{mg} / 10 \mathrm{ml}$.

${ }^{g}$ Riboflavin $5_{4}$-phosphate $\cdot 2 \mathrm{H}_{2} \mathrm{O}$, Na salt; assiy $96 \%$; California Corporation for Biochemical Research.

${ }^{h} 80 \mathrm{mg} /$ liter.

${ }^{i}$ This dilution is made before the solution is catalytically hydrogenated to form $\mathrm{FMNH}_{2}$; this provides solution $\mathrm{FH}$ for the fast reaction.

solutions, the working solutions, and the final reaction mixture. Stock solutions were stored in light-tight containers at $3^{\circ}$ for no longer than one month. Working solutions were prepared just before each set of assays and were stored in light-tight containers in an ice bath while the assays were performed.

For the $\mathrm{FMNH}_{2}$ or "fast" reaction the aldehyde-buffer working solution was identical to solution $\mathrm{AB}$ used for the slow reaction. The $\mathrm{FMNH}_{2}$ working solution ( $\left.\mathrm{FH}\right)$ was made by catalytic hydrogenation of a dilution of stock solution $\mathrm{F}$ described in Table 1. Figure 1 shows the apparatus used to prepare samples of $\mathrm{FNNH}_{2}$ for injection into the reaction medium. This apparatus permits the rapid preparation of a large number of stable samples of reduced flavin (or other biochemicals) 


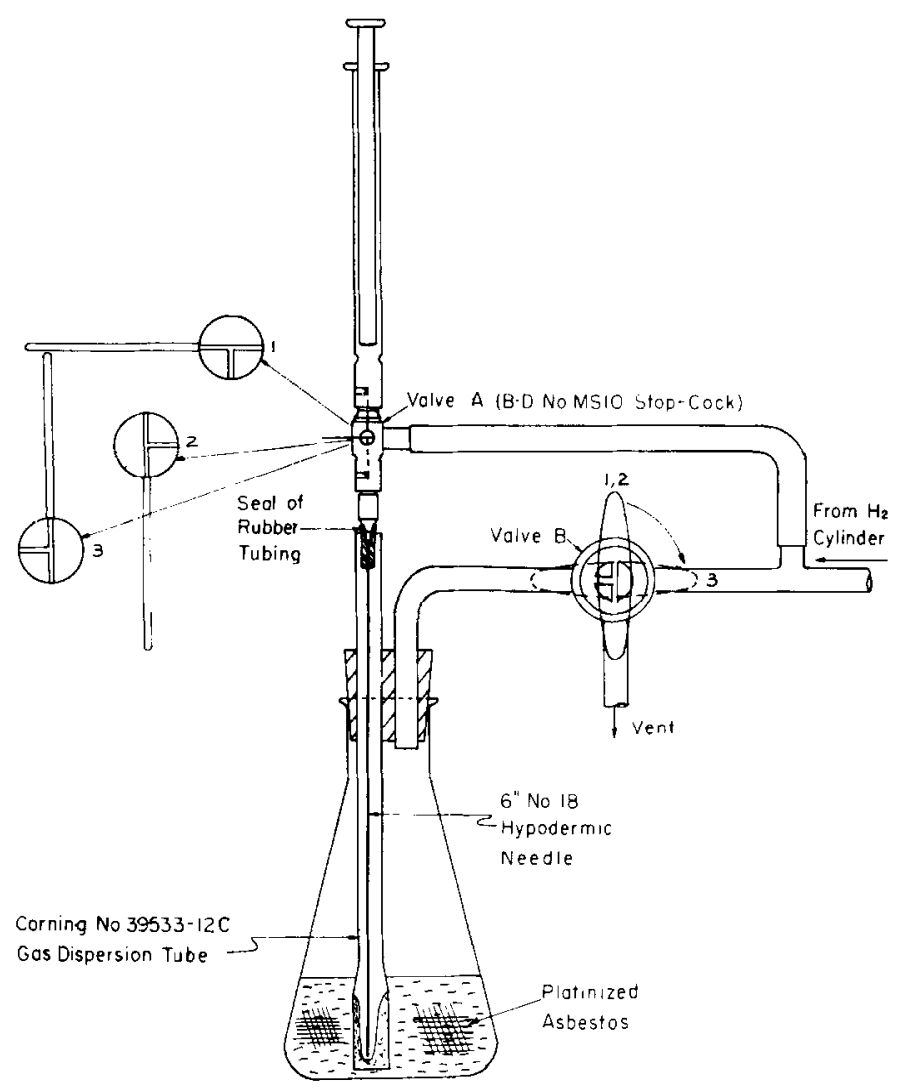

Fig. 1. Apparatus for preparing solution $\mathbf{F H}$. With the three-way valves $\mathbf{A}$ and $\mathbf{B}$ in position 1, gaseous hydrogen at $\mathbf{5}$ psi is directed through valve $A$, down the hypodermic needle, through the sintered glass cylinder which disperses the gas, and into the FMN solution containing platinized asbestos. Excess gas escapes through valve $B$ to the vent. The seal at the top of the dispersion tube may be loosened to expel trapped air. To collect a sample of $\mathrm{FMNH}_{2}$, a hypodermic syringe of desired capacity is attached to the top of valve $\mathrm{A}$ and, while holding the plunger in place, the valve is turned to position 2. By removing and inserting the plunger, the syringe is dried and degassed. Valves $\mathbf{A}$ and $\mathbf{B}$ are then turned to position 3 . This permits the hydrogen to be used as pressure to force the $\mathrm{FMNH}_{2}$ into the sintered-glass cylinder and to filter out the platinized asbestos. The syringe plunger is held down while the solution of $\mathrm{FMNH}_{2}$ rises up the hypodermic needle and into the syringe (the hydrogen initially in the needle will leak out through the dry syringe), whereupon the plunger is raised to collect a sample $0.2 \mathrm{ml}$ in excess of the volume desired. Valves $A$ and $B$ are then returned to position 1 ; the syringe is removed, fixed with a 1-in. 24-gage needle, and depressed by $0.1 \mathrm{ml}$ to expel air in the needle. The procedure may be repeated to prepare the desired number of samples in advance of their use. Immediatcly bcforc cnch samplc is injected into the reaction mixture, the $0.1 \mathrm{ml}$ excess solution is expelled to remove oxidized $\mathrm{FMNH}_{2}$ from the tip of the needle. 
free of the platinized asbestos catalyst and in any volume desired. The operation of the device is explained in the figure caption.

Figure 2 shows the photometric apparatus used to measure the luminous intensity produced by the luciferase reaction. The reaction is carried

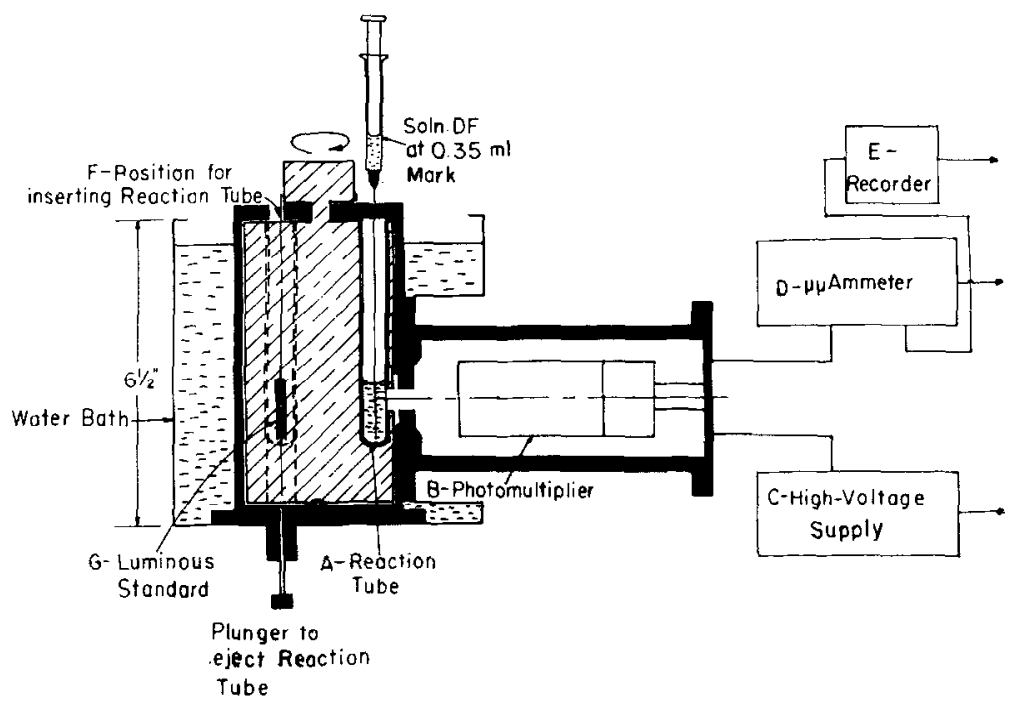

FIG. 2. Lateral cross section of photometer used for luciferase antivity assays. Included in the sketch is a photometer tube containing the $2.0 \mathrm{ml}$ of solution of CL, plus $0.5 \mathrm{ml}$ of solution $A B$. Solution $D F$ is about to be added. See text for explanation of other details.

out in a tube (A). A fixed fraction of the light produced by the reaction falls on the photomultiplier tube (B). The photomultiplier is a Dumont No. 6292 and is powered by a Hammer Model N401 high-voltage supply (C). The photomultiplier current is measured by a Keithly Model 410 micromicroammeter (D). The voltage applied to the photomultiplier was approximately 1100 volts, and the photomultiplier output ranged from 0.01 to $10 \mathrm{~m} \mu$. When the photomultiplier dark current is balanced out, the remaining current is proportional to the intensity of the luminescence generated in tube A. The luminous standard ( $G$ in Fig. 2) consisted of a Lucite tube containing a strontium-90-activated phosphor.

The tube holder was a cylinder with three holes bored $120^{\circ}$ apart. By revolving the cylinder, the reaction tube could be brought into position $F$, where it could be removed vertically. The reaction tubes were custom-made Pyrex test tubes selected for constant outside diameter (approximately $14 \mathrm{~mm}$ ). Transmission measurements showed that variation in luminous intensity due to differences among the tubes was not 
greater than $\pm 2 \%$. The cylinder housing was surrounded by a water bath to maintain constant temperature. Cooling coils fed by a commercial drinking water cooler were immersed in the bath to produce low temperatures for the fast reaction studies. A Texas Instrument Recorder (E) was used to trace the value of the luminous intensity throughout the course of the reaction.

\section{Definitions}

One Luminous Intensity Unit (LIU): The photometer current generated by a luminous standard designated in this laboratory as S-2.

Luciferase Activity: The maximum luminous intensity, expressed in LIU's, produced by the luciferase reaction when it is performed as described below.

One Luciferase Init $(L U)$ : That amount of active enzyme per milliliter of aqueous cell extract which, when prepared and assayed according to the procedure specified below, produces a luciferase activity equal to 1 LIU. Cell suspension samples producing luminous activities other than $1 \mathrm{LIU}$, however, do not have proportionately different units of luciferase, as will be pointed out below.

\section{Standard Assay Procedure Using the DPNH-FMN (Slow) Reaction}

Samples of cell suspension are prepared for assay in the following manner: A $20.0-\mathrm{ml}$ volume of suspension with a cell density between 0.5 and $20 \times 10^{8}$ cells $/ \mathrm{ml}$ is centrifuged at $15,000 \times g$ for $3-5$ min at $0^{\circ}$. The supernatant is discarded and in its place $5.0 \mathrm{ml}$ ice-cold distilleddeionized water is introduced from a 5 -ml hypodermic syringe. The syringe is fitted with a 6 -in. 20-gage hypodermic needle; the mixture of cells and water is forced up and down the needle to disperse the lysing cells thoroughly. The lysate is then centrifuged at $25,000 \times g$ for 10 min at $0^{\circ}$. The supernatant or cell extract (CL) which becomes the assay sample, is transferred in two $2.0-\mathrm{ml}$ portions to reaction tubes immersed in an ice bath. In dilution experiments, where less than $2.0 \mathrm{ml}$ of CL is assayed, the difference is made up with $\mathrm{H}_{2} \mathrm{O}$ or other diluent. The assay samples are stored for not longer than $1 \mathrm{hr}$.

The luciferase activity of the sample is determined as follows: A 1-ml hypodermic syringe fitted with a 6 -in. 18-gage needle is filled to the $0.5-\mathrm{ml}$ mark with solution $\mathrm{AB}$, leaving no air space in the needle. Another 1-ml syringe is fitted with a 6-in. 16-gage needle closed at the end and having nine $0.25-\mathrm{mm}$ diameter holes spaced along the last $2.0 \mathrm{~cm}$. This is filled to the $0.35 \mathrm{ml}$ mark with solution DF so that, with the $0.15 \mathrm{ml}$ contained in the needle, the total contents are $0.50 \mathrm{ml}$. Both syringes are placed in the $25^{\circ}$ water bath. At zero time, the reaction tube containing the $2.0-\mathrm{ml}$ 
sample of cell extract is transferred to the $25^{\circ}$ water bath and agitated gently. During this interval the photometer dark current can be zeroed and the voltage supply can be adjusted to give a current of $1.00 \mu \mathrm{a}$ with the luminous standard S-2. At $2.0 \mathrm{~min}$ the tube is removed from the water bath, wiped clean, and inserted rapidly into the photometer. The $0.5-\mathrm{ml}$ volume of solution $\mathrm{AB}$ is then introduced under the surface of the sample. The syringe containing solution DF is placed in position as shown in Fig. 2. At $2.5 \mathrm{~min}$, the contents of the syringe and the sample are quickly mixed by depressing the plunger, retracting it to flush out residual solution DF and depressing it again. Care is taken to avoid introducing air into the mixture because of the optical distortions produced by foam.

The maximum current occurring during the next $3 \mathrm{~min}$ is recorded. The maximum current in microamperes produced by the reaction is the luciferase activity in LIU, since the current produced by the luminous standard was set at $1 \mu \mathrm{a}$. The $5 \mathrm{ml}$ of cell extract prepared from each cell suspension sample enables this assay to be run in duplicate.

\section{Standard Assay Procedure Using the $\mathrm{FMNH}_{2}$ (Fast) Reaction}

Duplicate $2.0-\mathrm{ml}$ aliquots of the cell extract are prepared for assay in the manner described above. The photometer bath temperature is lowered to $12^{\circ}$ and maintained at this temperature thermostatically. Several $1-\mathrm{ml}$ syringes, each containing approximately $0.8 \mathrm{ml} \mathrm{FMNH}$ and fixed with a 1-in. 24-gage hypodermic needle, are prepared in advance by the procedure explained in Fig. 1 , and are stored in the $12^{\circ}$ water bath. Before zero time, $0.5 \mathrm{ml}$ of solution $\mathrm{AB}$ is taken up in another syringe fitted with a 6 -in. 18-gage needle and transferred to the water bath. At zero time the reaction tube containing the $2.0-\mathrm{ml}$ assay sample is transferred to the $12^{\circ}$ water bath and agitated gently. At $2.0 \mathrm{~min}$ the $0.5 \mathrm{ml}$ of solution $\mathrm{AB}$ is introduced under the surface of the sample, and the reaction tube is then transferred to the photometer. A syringe containing $\mathrm{FMNH}_{2}$ is quickly removed from the water bath and wiped dry, has its 24-gage needle exchanged for the 16-gage one used for solution DF above, is depressed to the 0.5 -ml mark to fill the needle with $\mathrm{FMNH}_{2}$, and is placed in position as shown in Fig. 2. At $2.5 \mathrm{~min}$, the syringe plunger is quickly depressed. The maximum photometer current produced by this reaction is then observed.

\section{Tests of Validity of Standard Assay Procedures}

An early step in the standard procedure consists of removing by highspeed centrifugation the lysed cell debris, which renders the extract turbid and affects the apparent luminous intensity of the luciferase reaction. 
Evidence that all the luciferase in the cell sample was present in the supernatant after this centrifugation was provided by $(a)$ determining the period of time for lysis necessary for the resulting cell extract to acquire maximum luciferase activity, $(b)$ resuspending the lysed cell debris after centrifugation and checking it for any residual luciferase activity, and (c) determining the effect of varying the volume of $\mathrm{H}_{2} \mathrm{O}$ used to lyse a given number of cells on the luciferase activity of the resulting extract. The last test was carried out by preparing a concentrated lysing cell suspension $(0.1 \mathrm{gm}$ cell/ml) and making serial dilutions before centrifugation; the activities of the resulting extracts were compared with those prepared by centrifuging the concentrated lysing cell suspension first and making the same serial dilutions after centrifugation. The slow reaction was used to determine luciferase activity.

The stability of the enzyme in the cell extracts when stored at 0 and at $25^{\circ}$ was determined by making serial dilution of a highly active extract to give concentrations in the ratio $4: 2: 1$. These three solutions were kept at $0^{\circ}$. The initial luminous activities were determined on each of them using the slow reaction. One-third of each solution was then transferred to the $25^{\circ}$ water bath and luminous activities were determined at approximately 15 -min intervals thereafter. At approximately hourly intervals the luminous activity of the solutions stored at $0^{\circ}$ was likewise determined.

The stability of FMN, DPNH, decanal, singly and in various combinations, was determined by appropriate combinations of stock solutions used to make the two working solutions. A single sample of cell extract sufficient for fifty luminous activity determinations was prepared and maintained in an ice bath. Four or five luminous activity determinations were made with each combination at intervals during a period of $2 \mathrm{hr}$.

The detergent Tween-20 was used to dissolve decanal in water. The optimum concentration of the detergent and decanal in solution $\mathrm{AB}$ and of DPNH and FMN in solution DF were determined individually by varying over a wide range the volume of the corresponding stock solution used to make up the working solution. For each working solution prepared, the slow reaction was run in duplicate on three dilutions of a cell extract.

The requirement of the fast reaction for rapid mixing of $\mathrm{FMNH}_{2}$ and sample was met by the injection technique described above. The adequacy of the technique was checked by substituting methylene blue for solution FH and visually observing inhomogeneities in the resulting mixture. A satisfactory working temperature was found by determining the reaction temperature permitting the maximum to be reached in not less than 2 sec after the mixing of the reactants was complete. To deter- 
mine the optimum requirement of $\mathrm{FMNH}_{2}$ for the fast reaction, FMN solutions were made up with various concentrations from 25 to $300 \%$ of the stock FMN concentration. These were reduced and used directly as solution $\mathrm{FH}$ in the fast reaction, and the luminous activities were determined for each.

The relation between luciferase activity and enzyme concentration was established by making serial dilutions of various cell extracts and determining the luciferase activity of each dilution by the standard assay procedure. The diluents used were (1) $\mathrm{H}_{2} \mathrm{O}$, (2) a cell extract identical to that being diluted but whose luciferase activity had first been extinguished by heating at $50^{\circ}$ for $30 \mathrm{~min}$, and (3) a cell extract identical to that being diluted but whose luminous activity had been almost completely extinguished by exposure to 0.25 megarad of ionizing radiation. The relation between luminous activity and dilution was investigated by plotting the data on log-log scales.

\section{RESULTS}

\section{Development of Luminescence in Individual Assays}

Some typical curves showing the development of luminescence by the slow reaction induced by DPNH + FMN are shown by curves $A$ to $D$ in Fig. 3. The mixing of solution DF with the $2.5 \mathrm{ml}$ of sample containing $0.5 \mathrm{ml}$ of solution $\mathrm{AB}$ was accomplished in about 2 sec. The lag

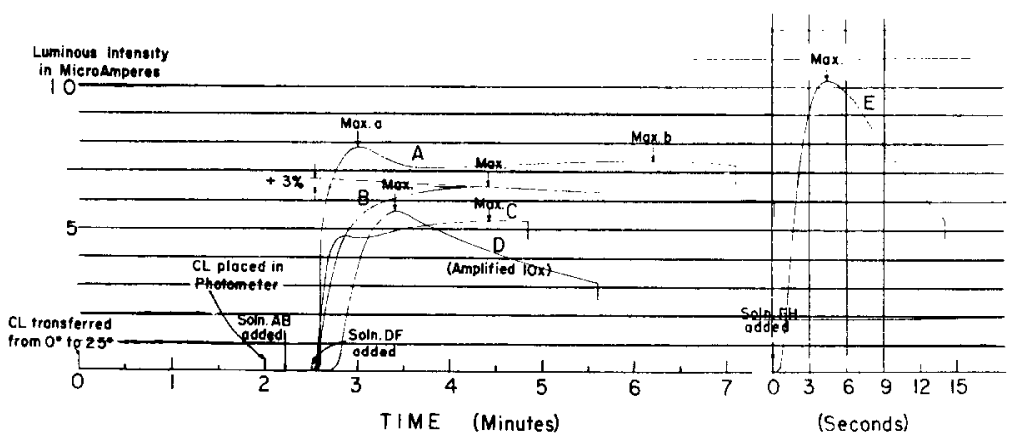

Fig. 3. Examples of types of tracings illustrating the course of in vitro luminous intensity with time generated by the slow reaction (curves A-D) and by the fast reaction (E). Zero seconds for curve $\mathrm{E}$ corresponds to the point $2.5 \mathrm{~min}$ on the lefthand scale with respect to sample warmup. Arrows denote position of maxima. Curve $B$ was allowed to run out for $7 \mathrm{~min}$ to determine the rate of decline of luminous intensity with time. This decay curve is extrapolated back to the beginning of the curve to estimate a correction $(+3 \%)$ of the observed maximum to compensate for loss of luciferase activity prior to attainment of maximum luminous intensity. See text for additional details. 
between the completion of the mixing and the appearance of luminescence may be considered the time during which $\mathrm{FMNH}_{2}$ is being generated by the oxidation of DPNH.

Once initiated, luminescence develops rapidly. Maximum luminescence may occur as early as $30 \mathrm{sec}$ after the first appearance of luminescence (curves A and C) or it may be reached gradually after $\mathbf{2}$ min (curve B). Double maxima occasionally occur (curves $\mathrm{A}$ and $\mathrm{C}$ ), possibly due to "burning off" of preformed $\mathrm{FMNH}_{2}$-aldehyde-luciferase complex. The luminous intensity of curve $D$ has been amplified 10 -fold to show the behavior of a weak extract. By far the most frequent curve, and the one on which this assay is based, is that represented by curve $B$. The luminous intensity always reaches a maximum by $3.5 \mathrm{~min}$ of reaction $(6 \mathrm{~min}$ after zero time), and declines thereafter. Agreement between successive duplicate samples is usually within $\pm 5 \%$.

Curve $\mathrm{E}$ of Fig. 3 represents the time course of development of luminescence by the fast reaction at a reaction temperature of $12^{\circ}$ when solution FH is added at time zero. The intensity reaches a maximum in 4-5 sec and declines without exhibiting a plateau. At room temperature, this reaction reaches a maximum in less than 0.5 sec, indicating that incomplete mixing of $\mathrm{FMNH}_{2}$ and extracts is not the limiting factor.

\section{Extraction of Luciferase from Bacterial Cells}

Varying the length of the lysing period had no effect on the maximum luciferase activity of the resulting cell extract. This is shown by luciferase activities of 1.56 and 1.49 after 1 and 30 min, respectively, between the time of resuspending collected cells and start of centrifugation. Thus any luciferase bound to the insoluble cell material is so tightly bound as to be unaffected by variations in extraction time.

Resuspension of lysed cell debris collected by high-speed centrifugation with a minimum of $\mathrm{H}_{2} \mathrm{O}$ yielded preparations with no detectable activity. On the basis of the dilution effect described below, this indicates that the cell debris together with adhering solution could not have contained more than 2-3\% of the luciferase originally extracted.

Varying the volume of $\mathrm{H}_{2} \mathrm{O}$ used to lyse a given number of cells gave the same result as adjusting to the same volume the concentrated extract after removal of cell debris. The failure to extract more enzyme by increasing the ratio of $\mathrm{H}_{2} \mathrm{O}$ to cell mass indicates that all extractable luciferase has been obtained.

\section{Stability of Luciferase in Samples Stored}

The change of luminous activity with time for cell extract samples of three different initial luminous activities each stored at 0 and $25^{\circ}$ was as 
follows: storage at $0^{\circ}$ for $3 \mathrm{hr}$ did not cause detectable loss of activity, but samples stored overnight at this temperature showed some loss depending on activity. The most concentrated extract retained $95 \%$ of its activity overnight, while the most dilute retained only about $70 \%$.

Storage at $25^{\circ}$ results in rapid loss of activity. Dilution of the sample increases the rate of loss. However, the loss of activity in samples of low luminous activity is negligible over a 6 -min period, the time required to perform the assay.

4. Optimum Combination and Requirement of Decanal, DPNH, and $F M N$ for Maximum Luciferase Activity with the DPNH-FMN Reaction

Tests of different combinations of FMN, DPNH, and decanal in working solutions showed that decanal in combination with either FMN or DPNH resulted in lower luminous activities than when it was added separately or with the buffer. The combination of decanal with buffer, and of FMN with DPNH, appeared to result in no deterioration even when stored several days at $3^{\circ}$.

Figure 4 shows the effect of various concentrations of Tween-20 in the working solution on the luciferase activity of a given sample of cell extract. The presence of a low percentage $(0.033 \%$ in the final reaction mixture) nearly doubles the luciferase activity whereas higher concentrations appear to interfere with the reaction.

Variation of the concentration of decanal in the reaction mixture for extracts of three different luciferase concentrations yielded the following results: Regardless of luciferase content, the $1.2 \mu$ moles $/ \mathrm{ml}$ decanal specified in the standard assay procedure is about twice the minimum for maximum activity. Increasing the concentration above the minimum decreases the maximum luminous activity slightly.

Variation of luciferase activity with concentration of DPNH in the reaction mixture for extracts of three different luciferase concentrations gave these results: The concentration chosen for use in the assay $(0.27$ $\mu \mathrm{moles} / \mathrm{ml}$ ) is approximately the minimum for maximum activity. A large increase in DPNH concentration above this minimum may cause a slight increase in activity. The small rate of change of luminous activity with DPNH concentration in the range of the minimum does not appear to vary with the level of activity in the extracts.

Figure 5 shows the variation of luciferase activity with concentration of FMN in the reaction mixture for extracts of three different luciferase concentrations. All four curves confirm the existence of an optimum rather than a minimum concentration of FMN for maximum luminous activity. Concentrations above the optimum appear to be inhibitory. The higher the luciferase content of the sample, the more rapidly the 


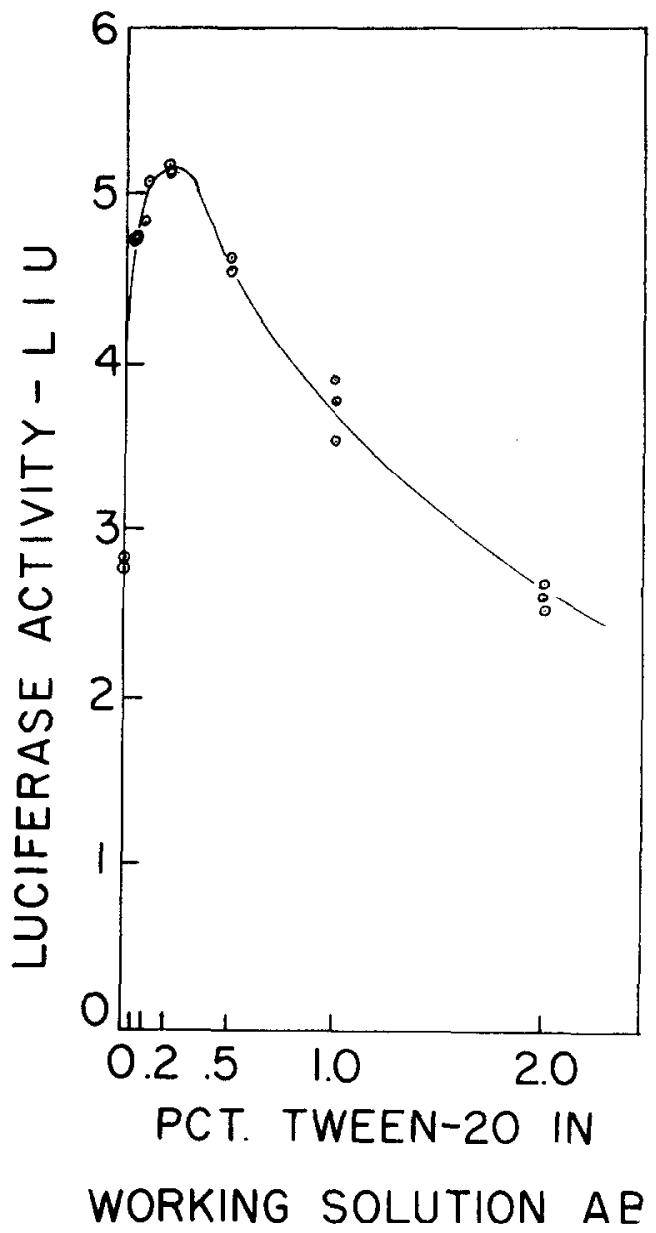

Fig. 4. Effect of concentration of Tween-20 in working solution $A B$ on luciferase activity generated by the slow reaction.

curve rises and falls with increasing FMN concentration. The optimum concentration of FMN for the least active sample (curve D) was 1.0 $\mu \mathrm{mole} / \mathrm{ml}$; that for the sample of moderate activity (curve C), 1.9 $\mu \mathrm{moles} / \mathrm{ml}$; and that for the most active sample (curves $\mathrm{A}$ and $\mathrm{B}$ ), $2.1 \mu \mathrm{moles} / \mathrm{ml}$. Curves A and B were obtained with the same sample at different times. Since one concentration of FMN must be established for the assay, a concentration of $1.7 \mu \mathrm{moles} / \mathrm{ml}$ was adopted (see Table 1).

Figure 5 shows that this concentration results in an error of $-1.3 \%$ in the case of the most active sample and an error of $+6 \%$ in the case of the sample of least activity. 


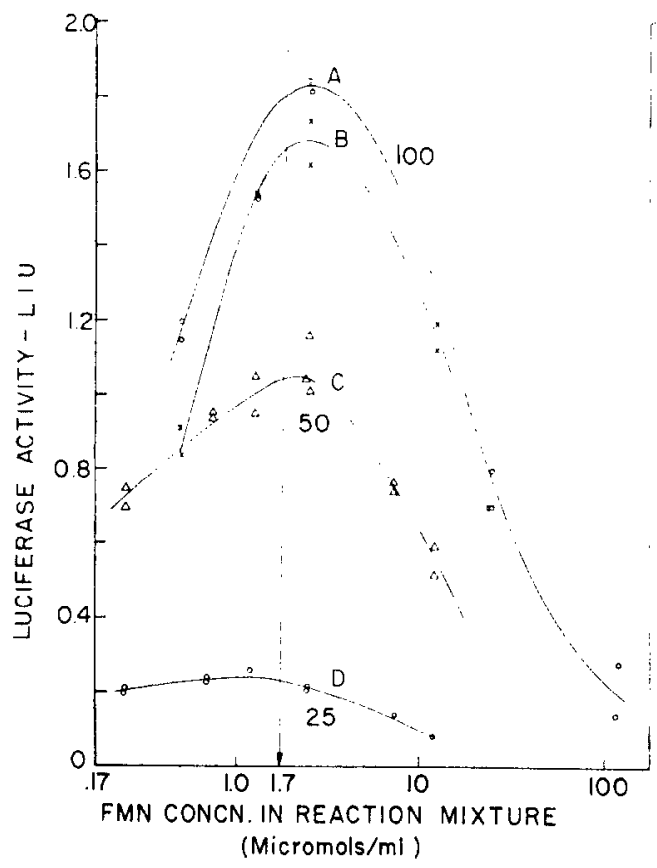

Fig. 5. Effect of concentration of FMN in reaction mixture on luciferase activity for a CL of high activity (100\% of initial stock concentration used, curves $\mathrm{A}$ and $B$ ), of moderate activity ( $50 \%$ of concentration of stock CL, curve C), and of low activity (25\% of concentration of stock CL, curve D). Curve B represents the same extract for curve $A$ after storage at $3^{\circ}$ overnight. The long vertical arrow represents the concentration adopted for the standard assay procedure.

\section{Optimum Conditions for Maximum Luminous Activity with the $\mathrm{FMNH}_{2}$ (Fast) Reaction}

The tests with methylene blue showed that the best technique to achieve rapid mixing of reactants consisted of rapidly ejecting the syringe contents laterally outward into the $2.5 \mathrm{ml}$ of reaction mixture through nine $0.25-\mathrm{mm}$ holes spaced along the bottom $2.0 \mathrm{~cm}$ of a 6 -in. 16-gage hypodermic needle whose end is closed off. A reaction temperature of $12^{\circ}$ was found to slow the reaction sufficiently so that the maximum luminous intensity was not reached for approximately 2 sec following mixing of reactants.

Figure 6 shows the variation in lueiferase activity with $\mathrm{FMNH}_{2}$ concentration for the "fast" reaction carried out by the standard procedure. The results are similar to those obtained with various FMN concentrations in the slow reaction, except that the standard concentration of $\mathrm{FMNH}_{2}$ found to be optimum with the fast reaction was $12 \times$ that of 


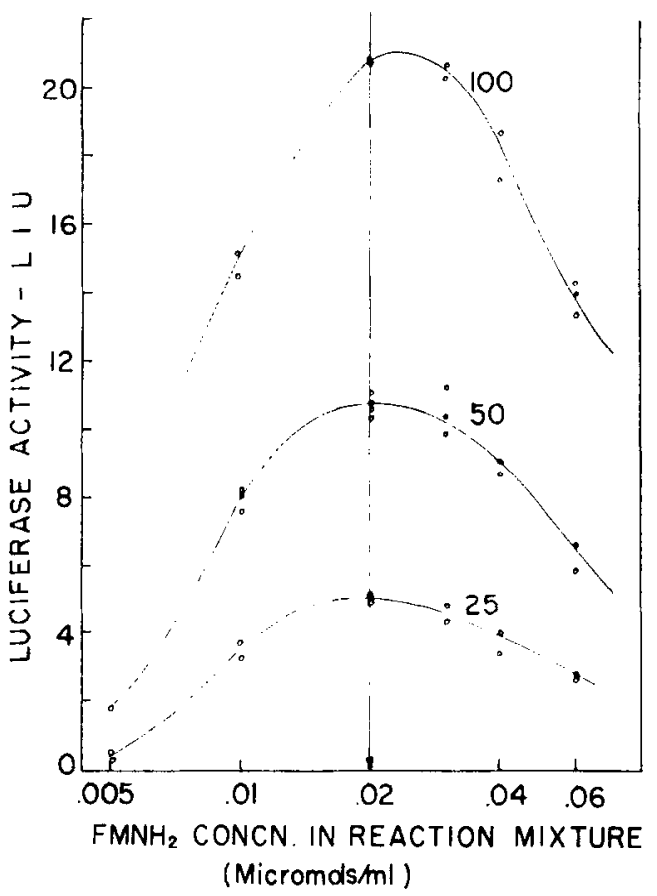

FIG. 6. Effect of concentration of reduced $\mathrm{FMN}\left(\mathrm{EMNH}_{2}\right)$ in the reaction mixture on the luciferase activity of a CL of high activity (100\% of initial stock concentration used), of moderate activity ( $50 \%$ of concentration of stock CL), and of low activity ( $25 \%$ of concentration of stock CL). The long vertical arrow represents the concentration adopted for the standard assay procedure.

FMN for the slow reaction. A slightly higher $\mathrm{FMNH}_{2}$ concentration appears to be optimum for concentrated rather than for diluted enzyme preparation.

\section{Relation between Luciferase Concentration and Luminous Activity with the Slow Reaction}

Figure 7 shows the relation between luciferase concentration and luciferase activity graphed on log-log coordinates for a number of extracts prepared on various dates. The relationships appear to be linear on such plots down to low luciferase activities. The relationship between activity and concentration is therefore of the form $A=B(L)^{k}$, where $A$ is luciferase activity, $(L)$ is concentration of luciferase, $B$ is a constant reflecting choice of units, and $k$ is a constant governing the rate of change of luciferase activity with concentration. When luciferase activity is expressed in LIU and luciferase concentration in milliliters of luciferase 


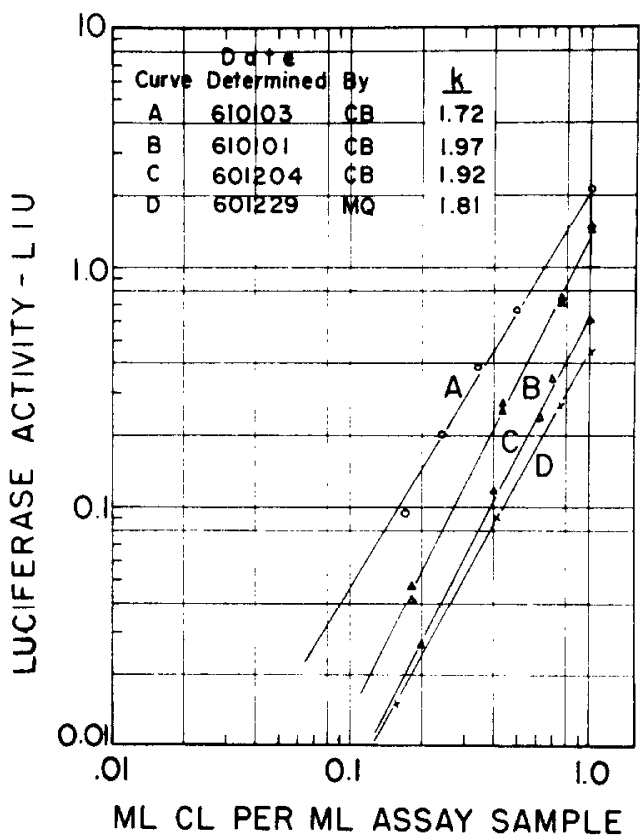

F'IG. 7. Comparison of $\log$ luciferase activity-log enzyme concentration relation for cell extracts from various experiments. Diluent is distilled water in all cases. The values of $k$ are those in $A=(E)^{k}$, where $A=$ luciferase activity in LIU and $(E)$ is concentration of enzyme preparation (CL) in the assay sample. The dates and initials signify that the four curves represent different cell extracts.

preparation (extract) per milliliter of assay sample, $B$ becomes unity. The slope of the lines in Fig. 7 correspond to the value of $k$.

Figure 8 shows the effect of using different diluents on the log-log relationship described above. Curve $\mathrm{A}$ represents the normal case, in which $\mathrm{H}_{2} \mathrm{O}$ was the diluent, as were those in Fig. 11 . Curve $\mathrm{B}$ is the same extract diluted in the same manner using as diluent additional extract whose activity was extinguished by mild heating. This line was very nearly identical to that produced by using $\mathrm{H}_{2} \mathrm{O}$ as diluent. Thus the effect of dilution with $\mathrm{H}_{2} \mathrm{O}$ is not due to the dilution of any unknown factor in the cell extract which is involved in the luciferase reaction and which is stable to mild heating.

Curve $\mathrm{C}$ is that produced by using irradiated extract as diluent. A small residual activity remained in the diluent after it received $\mathbf{0 . 2 5}$ megarad. In the region of high extract concentration, where the activity was large compared to that of the diluent, the line is very nearly identical to lines A and B. At lower extract concentrations, the luminous intensity contributed by the luciferase in the diluted extract is so dimin- 


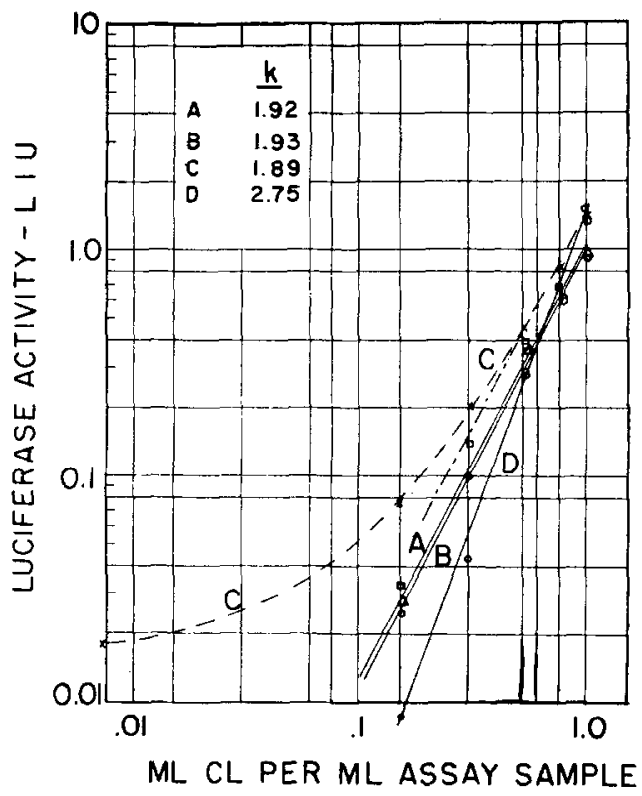

FIg. 8. Comparison of $\log$ luciferase activity-log enzyme concentration relationships for CL diluted with different diluents. Curve $A$, the diluent is DDW. Curve $B$, the diluent is a portion of the same CL previously heat-inactivated. Curve $C$, the diluent is a portion of the same CL whose luciferase activity was reduced to a low level by irradiation; $k$ for this curve was obtained from the projection of its upper portion. Curve D represents the dilutions shown in curve $A$ after 5 days of storage at $3^{\circ} \mathrm{C}$. The significance of $k$ is explained in Fig. 11 .

ished that the amount present in the diluent itself begins to assert itself sufficiently to cause the line to deviate from linearity.

Curve D represents the same dilutions represented by curve $A$ after additional portions of each dilution had been stored at $3^{\circ}$ for five days. There is a marked change in slope, indicating that a particular value for the slope is useful only when the assays are completed within a few hours.

Figure 9 shows the effect of diluting with $\mathrm{H}_{2} \mathrm{O}$ cell extracts prepared from bacterial suspensions which had been exposed to $0,10,20$, and 30 kilorads of gamma radiation (3). There is a slight effect of irradiation on the slope of the log-log when compared to that of the controls. However, this deviation does not appear serious in the region where the relationships are used to estimate units of luciferase activity per milliliter of extract. It may be noted that extracts prepared from irradiated cells contained more rather than less luciferase activity. Further details of this investigation may be found by consulting reference (3).

The value of $k$ shown in Figs. 7-9 and obtained in other experiments 


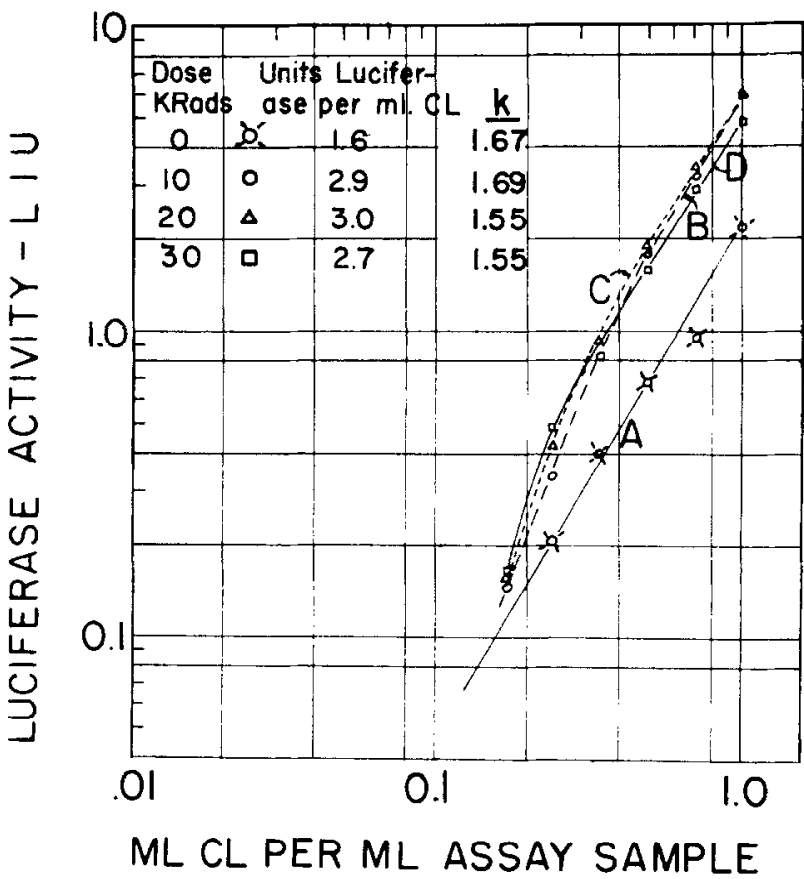

Fia. 9. Comparison of $\log$ luciferase activity-log enzyme concentration relation for CL's obtained from cell suspensions receiving 0 (curve A), 10 (curve B), 20 (curve $\mathrm{C}$ ), and 30 kilorads of gamma radiation (curve D). The significance of $k$ is explained in Fig. 11.

ranged from 1.55 to 2.75 . The variation is least among various extracts prepared from the same cell suspension and assayed at the same time, as shown by the values of $k$ for curves A, B, and C in Fig. 8 and for the linear portion of the four curves in Fig. 9. Irradiation of the cells before assay appears to have much less effect on the value of $k$ (Fig. 9) than does storage of the extract for several days at $4^{\circ}$ (curve D, Fig. 8). Extracts prepared from different cell suspensions, however, have a wide difference, as shown by an average of 1.62 for those in Fig. 9 to an average of $\mathbf{1 . 9 1}$ for those in Fig. 8.

\section{Luciferase Activity Determined by the Fast Reaction}

Figure 10 shows the variation of luciferase activity determined by the fast reaction at $12^{\circ}$ with concentration of luciferase as determined by dilution of extracts prepared from two cell suspensions. The extract from one was assayed at successive daily intervals. When plotted on linear coordinates, a linear relation can be shown for the higher concentrations but not for the lower. An extrapolation of the linear relation for high concentrations does not pass through the origin. The intercept of the ex- 


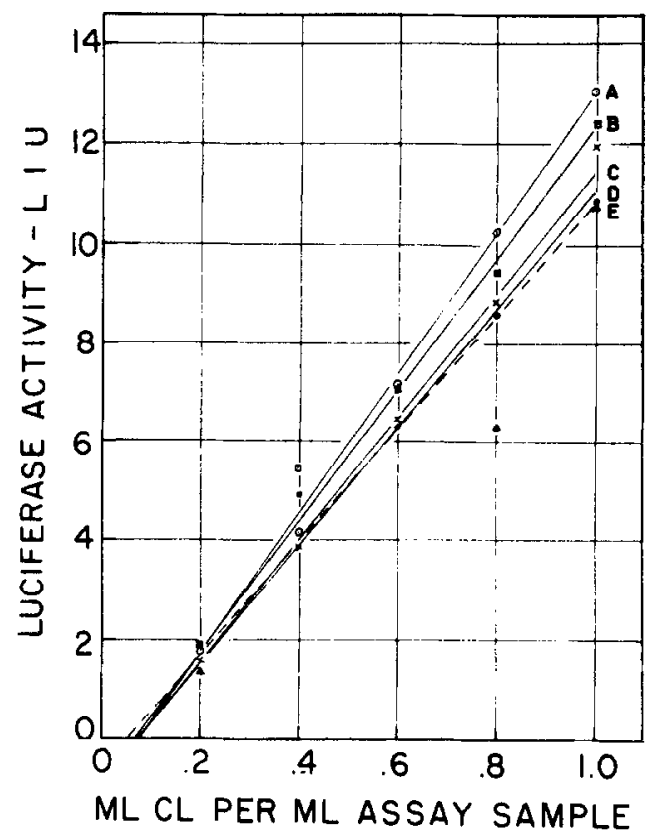

FIg. 10. Effect of dilution with DDW on luciferase activity of two CL's (curves $A$ and $E$ ) prepared at different times as determined by the fast reaction. Curves B, $\mathrm{C}$, and $\mathrm{D}$ represent the results with the CL used for $\mathrm{A}$ after storage under refrigeration for 1, 2, and 3 days, respectively. Storage does not change appreciably the intercept of the abscissa $(0.075 \mathrm{ml} \mathrm{CL} / \mathrm{ml}$ assay sample), whereas CL's prepared at another time do not have the same intercept $(0.05 \mathrm{ml} \mathrm{CL} / \mathrm{ml}$ assay sample $)$.

trapolation on the concentration scale varies with the particular extract tested (5.2 to $7.5 \%$ in Fig. 10). The above activity-concentration relation would be applicable only for extracts containing more than $1 \mathrm{LU} /$ $\mathrm{ml}$.

Figure 11 shows the relationship between the luciferase activities generated by the two reactions at $12^{\circ}$ using various dilutions of a cell extract. This relation, when plotted on log-log paper, is very close to that of the luciferase activities determined by the slow reaction plotted against luciferase concentration. The value of $k$ is lower than the lowest value found for the slow reaction. The luciferase activity determined by the fast reaction varies from two to five times that by the slow reaction, depending on whether the luciferase content is high or low, respectively.

\section{Determination of Units of Luciferase}

In the conversion of luciferase activities determined by the slow reaction to units of luciferase per milliliter, it will be necessary to deter- 


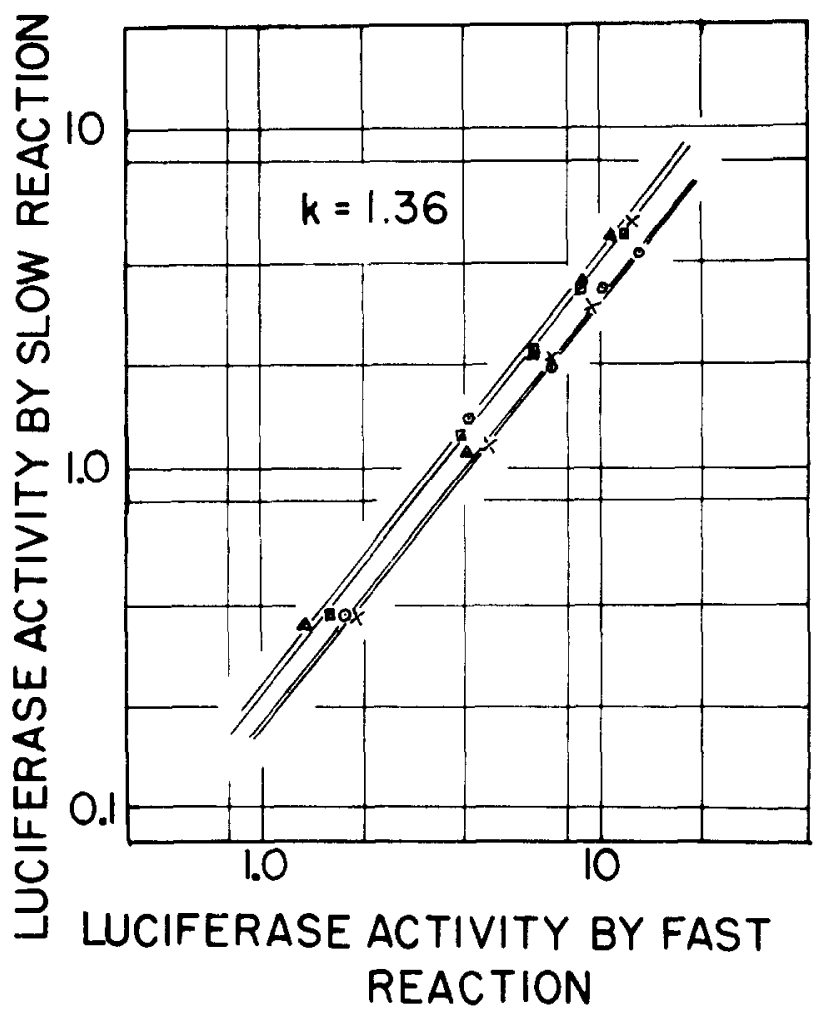

FIG. 11. Relationship between luciferase activities produced by the fast reaction and those produced by the slow reaction for a number of dilutions of a CL. Both reactions were carried out at $12^{\circ} \mathrm{C}$. The value of $k$ is the slope of the $\log -\log$ plots and corresponds to $k$ in $A=(E)^{k}$ in Figs. 7-9 and 11 .

mine the value of $k$ applying to extracts from each cell suspension assayed. This may be obtained by determining the luciferase activities, $A_{1}$ and $A_{1 / 2}$, of the undiluted and of a $1: 2$ dilution (with $\mathrm{H}_{2} \mathrm{O}$ ), respectivcly, of the frcsh extract, in which casc:

$$
h:=\frac{\log A_{1}-\log A_{1 / 2}}{0.301}
$$

The units of luciferase in this cell extract may then be calculated as follows:

$$
\mathrm{LC} / \mathrm{ml}=\frac{1}{\operatorname{antilog}\left(-\log A_{1} / k\right)}
$$

If the values of $k$ applicable to each of a series of extracts do not vary by more than $\pm 2.5 \%$, a single average value of $k$ may be used without 
an error greater than $\mathbf{\pm 2} \%$ in resulting values of luciferase concentration. This would permit luciferase activities to be determined graphically by use of a conversion line on log-log coordinates having a slope equal to $k$ and passing through the point $1 \mathrm{LIU}=1 \mathrm{LU} / \mathrm{ml} . \mathrm{A} \pm 2.5 \%$ error in the value of $k$ will not be exceeded if the average deviations in the determination of $I_{1}$ and $I_{1 / 2}$ do not exceed \pm 1.6 and $\pm 2.3 \%$, respectively, for values of $I_{1}$ and $I_{1 / 2}$ in the neighborhood of 5 and $1.4 \mathrm{LIU}$, respectively.

The determination of luciferase concentration in units $/ \mathrm{ml}$ from luciferase activity measured by the fast reaction also requires that two determinations be made on each cell extract. If one determination is made on an undiluted sample $\left(A_{1}\right)$ and another on a $50 \%$ dilution $\left(A_{1 / 2}\right)$, then the $\mathrm{LU} / \mathrm{ml}$ may be calculated as follows:

$$
\mathrm{LU} / \mathrm{ml} \text { (fast reaction) }=\frac{2 A_{1}}{2+\left(\frac{A_{1}-2 A_{1 / 2}}{A_{1}-A_{1 / 2}}\right)\left(A_{1}-1\right)}
$$

Luciferase concentrations may be determined graphically from a conversion plot if it is found that the slope of the plot and its intercept with the ordinate referring to concentration of extract does not vary appreciably from one cell extract to another.

Table 2 shows the results of applying the standard assay procedure

TABLE 2

Correlation of Sample Size with Amount of Luciferase Found

\begin{tabular}{ccc}
$\begin{array}{c}\text { Vol. of sample of } \\
\text { cell suspension }\end{array}$ & $\begin{array}{c}\text { Luciferase } \\
\text { units/sample }\end{array}$ & $\begin{array}{c}\text { Luciferase units/ml } \\
\text { cell suspension }\end{array}$ \\
\hline 5 & 1.8 & 0.36 \\
10 & 3.5 & 0.35 \\
15 & 5.8 & 0.39 \\
20 & 7.6 & 0.34 \\
\hline
\end{tabular}

using the slow reaction to various size samples of a single cell suspension. The relation between volume of sample and units of luciferase activity appears to be a reasonably constant one. It suggests that the average of duplicate determinations give a value of $\mathrm{LU} / 10^{9}$ cells to within $\pm 10 \%$.

\section{DISCUSSION}

The rapidity with which Photobacterium fischeri cells lyse when suspended in distilled and deionized water is probably a result of their being grown in media of high tonicity (equivalent to $0.6 \mathrm{M} \mathrm{NaCl}$ or 
$3.5 \%$ ). Some lysis has been observed to occur with cells suspended in as much as $0.5 \% \mathrm{NaCl}$. The apparent absence of activity in the cell debris indicates that the enzyme passed quantitatively into the aqueous phase. High-speed centrifugation results in a water-clear extract which seldom exceeds $0.25 \%$ protein concentration. The enzyme appears sufficiently stable for the duration of an assay series when kept at ice temperature, and at $25^{\circ}$ for the duration of a particular assay.

The significance of the unit of luciferase defined in this report depends upon the geometric specifications of the particular photometer housing used and on the particular luminous standard with which the luminous intensities are compared at the time. A chemiluminescent reaction whose quantitative chemical change is related to a known light output would be desirable to define a unit which would be applicable from one laboratory to another, as in the case of enzyme rcactions measured on a chemical basis.

The "slow" reaction is more convenient to use as a basis for the assay because, at room temperature, the maximum luminous intensity prevails for a period longer than the response time of the photometer and the time needed to observe the ammeter reading. The luciferase activities determined in crude extracts by the "fast" reaction are not sufficiently proportional to concentration to offer an advantage over the "slow" reaction.

The fading of luminescence is characteristic of the in vivo as well as of the in vitro luciferase reaction. Part of this fading is believed to be associated with a progressive inactivation of the enzyme as it participates in the reaction (3). The fact that it occurs indicates the possibility that some luciferase activity may be lost before the maximum is reached (see curve $B$ in Fig. 2). It is believed that this is a negligible source of error because the rate of decline following the maximum is sufficiently low to indicate little loss before the maximum is reached.

The optimum requirement of $\mathrm{FMNH}_{2}$ in the fast reaction agrees with the minimum requirement for maximum activity in active preparations $(0.2 \mu \mathrm{mole} / \mathrm{ml})$ as shown by McElroy and Green (8); the concentration of DPNH used in the present procedure is about five times the minimum requirement $(0.05 \mu \mathrm{mole} / \mathrm{ml})$ demonstrated by Strehler and Cormier (9). The optimum concentration of aldehyde used in previous work was not specified, but is probably considerably lower than that used here.

What is known about the luciferase reaction indicates that it is rather complex. Because the oxidation of one molecule of $\mathrm{FMNH}_{2}$ does not furnish the energy of one photon of visible light, two molecules are believed to be involved, with a luciferase-aldehyde complex functioning to 
combine the energy of both. The aldehyde is believed to undergo peroxidation in this process. While oxygen reacts in some way with the luciferase-aldehyde-peroxide- $\mathrm{FMNH}_{2}$ complex, it rapidly oxidizes available $\mathrm{FMNH}_{2}$ and thereby competes with the light-emitting step. The reaction is further complicated by being inhibited by FMN, which presumably competes with the reduced form for available enzyme sites, or leads to increased formation of riboflavin, which is known to inhibit the reaction. However, since dilution of extracts with $\mathrm{H}_{2} \mathrm{O}$ has the same effect on luciferase activity as does dilution with heat-inactivated extract, it is not likely that use of crude rather than purified extracts would make the assay more accurate, assuming no enzyme was lost in purification.

It is not surprising that the rate of the slow reaction is sharply diminished by dilution. Judging by the 2 - to 5 -fold greater maximum light intensity of the fast reaction over that of the slow reaction when both are carried out under the same conditions (Fig. 11), it is probable that, in the light-emitting step of the slow reaction, the substrate $\mathrm{FMNH}_{2}$ is limiting. Dilution of the enzyme should thus cause more than a proportional decrease in maximum activity. What portion of the $\mathrm{FMNH}_{2}$ generated is lost to autoxidation and how this portion varies with dilution are not known. The fact that the enzymes must presumably combine with more than one molecule of reduced flavin and the possibility that the DPNH oxidase which generates the $\mathrm{FMNH}_{2}$ and the luciferase which consumes it may be part of a multienzyme, as suggested by McElroy and Green (8), adds to the difficulty of analyzing the effect of enzyme concentration on the luminous activity.

\section{SUMMARY}

The bacterial luciferase reaction carried out in vitro can be used as a basis for a semiquantitative assay of active luciferase in bacterial cells. Relations between maximum luminous intensity generated and the amount of enzyme present can be established for luciferase and for the combination of DPNH oixdase and luciferase. A definition is suggested for a unit of luciferase activity. It is believed that the assay procedure described can be made accurate to within $\pm 10 \%$.

\section{REFERENCES}

1. Hug, O., ANd Wolfw, I. In "Progress in Radiobiology," Proc. 4th Intern. Conf. Radiobiol., Cambridge, England, August, 1956. C. C Thomas, Springfield, Ill., 1956.

2. Whipple, G. H., J. Cellular Comp. Physiol. 43, 415-423 (1954).

3. Burns, C. F., Nevill, A. D., AND Whipple, G. H., Science 135, 430-32 (1962).

4. Burns, C. H., Nevill, A. D., AND Whipple, G. H., Luminescence and luciferase on Photobacterium fischeri cell suspensions (in preparation). 
5. Strehler, B. L., ANd Cormier, M. H., J. Biol. Chem. 211, 213-225 (1954).

6. McElroy, W. D., Hastings, J. W., Sonnenfeld, V., ANd Coulombre, J., Science 118, 385-6 (1953).

7. Strehler, B. L., J. Am. Chem. Soc. 75, 1265 (1953).

8. McElroy, W. D., ANd Green, A. A., Arch. Biochem. Biophys. 56, 240 (1955).

9. Strechler, B. L., and Cormier, M. J., Arch. Biochem. Biophys. 53, 138 (1954).

10. Farghal Y, A. H., J. Cellulat Comp. Physiol. 36, 165 (1950). 